\title{
PERBANDINGAN KEMAMPUAN MASTIKASI PEREMPUAN MENOPAUSE DAN PASCAMENOPAUSE PENGGUNA GIGI TIRUAN LENGKAP
}

\section{COMPARISON OF MASTICATORY ABILITY BETWEENMENOPAUSAL AND POSTMENOPAUSAL WOMEN COMPLETE DENTURE WEARER}

\author{
Elvina Josephine, Sri Wahyuningsih Rais, Shanty Chairani \\ Bagian Kedokteran Gigi dan Mulut \\ Fakultas Kedokteran Universitas Sriwijaya \\ Korespondensi email : shanty.c@fk.unsri.ac.id
}

\begin{abstract}
Abstrak
Mastikasi merupakan proses kompleks yang bertujuan untuk memproses makanan menjadi bolus sehingga membantu dalam proses penyerapan nutrisi oleh tubuh. Kehilangan hormon estrogen pada kondisi menopause menyebabkan penurunan dari kepadatan tulang, aktivitas otot mastikasi, laju alir saliva, serta kehilangan gigi sehingga mempengaruhi kemampuan mastikasi. Pengunaan gigi tiruan lengkap merupakan salah satu upaya untuk meningkatkan kemampuan mastikasi. Tujuan penelitian ini adalah untuk membandingkan kemampuan mastikasi pada perempuan menopause dan pascamenopause pengguna gigi tiruan lengkap. Penelitian analitik observasional dengan desain potong lintang dilakukan pada 30 subjek pengguna gigi tiruan lengkap di RSKGM, Sumatera Selatan, yang terdiri dari dua kelompok yaitu kelompok perempuan menopause dan kelompok perempuan pascamenopause. Kemampuan mastikasi diukur menggunakan metode permen karet dengan color-changeable chewing gum. Setiap subjek diinstruksikan untuk mengunyah 1 buah permen karet sebanyak 100 kali. Perubahan warna pada permen karet diukur secara visual dan dibagi menjadi kategori baik dan buruk. Data dianalisa dengan uji Chi-square. Hasil penelitian menunjukkan kelompok menopause pengguna gigi tiruan lengkap memiliki kemampuan mastikasi yang lebih baik (100\%) daripada kelompok pascamenopause pengguna gigi tiruan lengkap $(26,7 \%)$ dan menunjukkan perbedaan yang bermakna $(\mathrm{p}<0,05)$. Kesimpulan dari penelitian ini adalah kemampuan mastikasiperempuan menopausepengguna gigi tiruan lengkap lebih baik dibandingkan perempuan pascamenopausepengguna gigi tiruan lengkap.
\end{abstract}

\section{Kata kunci:}

Color-changeable chewing gum,gigi tiruan lengkap, kemampuan mastikasi, menopause, pascamenopause

\begin{abstract}
Mastication is a complex process that aims to process the food into a bolus, which help in the absorption process of nutrients into the body. Loss of estrogen in menopausal condition causes decreased of bone density, muscle activity, salivary flow rate, and tooth loss that affect the ability of mastication. Wearing complete dentures can improve the masticatory ability. The aim of the present study was to compare the masticatory ability in menopausal and postmenopausal women complete denture wearers.bservational analytic study with cross sectional design was conducted on 30 female subjects complete denture wearers
\end{abstract}


at RSKGM, South Sumatra. Subjects consisted of two groups that were menopause group and postmenopausal group. Masticatory ability was measured using the chewing gum method with colorchangeable chewing gum. Each subject was instructed to chew 1 piece of gum for 100 strokes. Color changes in chewing gum were visually measured and categorize into good and poor masticatory ability. Data were analyzed by Chi-square test. The results showed the menopausal women complete denture wearers group had better mastication ability (100\%) than the postmenopausal women complete denture wearers group (26.7\%). There was a significant difference in masticatory ability between the groups $(\mathrm{p}<0.05)$. In conclusion, masticatory ability of menopausal women complete denture wearer is better than postmenopausal women complete denture wearer.

\section{Keywords:}

Color-changeable chewing gum, complete dentures, mastication ability, menopause, postmenopause.

\section{Pendahuluan}

Mastikasi bertujuan untuk memproses makanan menjadi bolus yang mudah untuk ditelan dan membantu dalam proses penyerapan nutrisi ke dalam tubuh untuk memenuhi kebutuhan energi dasar dalam tubuh. ${ }^{1}$ Komponen penting dalam mastikasi antara lain gigi geligi, sendi temporomandibula, saliva, dan otot-otot mastikasi. ${ }^{1,2}$ Faktor-faktor yang dapat mempengaruhi mastikasi diantaranya kekuatan mastikasi, aktivitas otot mastikasi, dan laju alir saliva. ${ }^{3}$ Faktor tersebut dapat dikaitkan dengan usia. Penelitian Lamster dkk melaporkan bahwa usia bukan merupakan faktor resiko yang secara langsung menyebabkan penurunan kemampuan mastikasi, tetapi menjadi faktor yang mempengaruhi kekuatan mastikasi dan laju alir saliva, yang keduanya menurun seiring bertambahnya usia. ${ }^{4}$

Seiring bertambahnya usia, secara fisiologis, perempuan mengalami masa klimakterium yaitu terjadi gangguan metabolisme hormonal yang dikenal sebagai masa premenopause, menopause, dan pascamenopause. Menopause merupakan suatu periode berhentinya siklus menstruasi pada usia antara 45-55 tahun.Masa pasca menopause terjadi 3-5 tahun setelah masa menopause. ${ }^{5}$ Pada masa menopause, terjadi penurunan jumlah hormon estrogen yang berlanjut dari masa premenopause. ${ }^{6,7}$

Hormon estrogen memiliki peran penting dalam tubuh sehingga mempunyai pengaruh pada sebagian besar jaringan di tubuh. ${ }^{6}$ Hormon estrogen merupakan golongan hormon steroid yang berfungsi utama sebagai hormon seks pada perempuan. ${ }^{8}$ Hormon estrogen dapat dihasilkan oleh testis, ovarium, adrenal, dan plasenta. ${ }^{8}$ Berkurangnya kadar estrogen berhubungan dengan penurunan kepadatan tulang, kehilangan perlekatan jaringan periodontal, serta menjadi faktor terjadinya osteoporosis yang juga mempengaruhi resorpsi tulang alveolar, hilangnya gigi, serta terjadinya penurunan massa dan kekuatan otot (sarkopenia) yang akan mempengaruhi kemampuan mastikasi. 5,9,10 Lama menopause dapat mempengaruhi besar penurunan densitas tulang yang akan mengakibatkan kehilangan gigi yang berperan dalam proses mastikasi. ${ }^{5}$ Beberapa dampak fungsional yang dapat ditimbulkan akibat kehilangan gigi antara lain 
penurunan kemampuan mastikasi, kelainan proses bicara, dan gangguan pada sendi temporomandibular. ${ }^{11}$ Penelitian Pamungkas dkk menunjukkan bahwa perempuan menopause memiliki kemampuan mastikasi yang lebih rendah dibandingkan perempuan yang belum menopause. ${ }^{12}$ Riadiani dkk juga melaporkan bahwa terdapat hubungan antara lama menopause dengan kemampuan mastikasi, yaitu perempuan yang telah mengalami menopause selama lebih dari 5 tahun mempunyai kemampuan mastikasi yang lebih buruk dibandingkan perempuan yang telah mengalami menopause kurang dari 5 tahun. ${ }^{5}$

Perawatan menggunakan gigi tiruan lengkap menjadi perawatan utama selama beberapa dekade karena daya tarik estetika dan perawatan yang mudah. ${ }^{13}$ Gigi tiruan lengkap adalah gigi tiruan yang menggantikan seluruh gigi dan struktur yang telah hilang pada rahang atas atau rahang bawah, ataupun keduanya. ${ }^{14}$ Penelitian Matsuda dkk menunjukkan bahwa perawatan menggunakan gigi tiruan lengkap akan meningkatkan kemampuan mastikasi dengan nilai kekuatan gigit gigi tiruan lengkap sebesar $165 \mathrm{~N} .{ }^{15}$ Tujuan penelitian ini adalah untuk membandingkan kemampuan mastikasi perempuan menopause dan pascamenopause pengguna gigi tiruan lengkap di Palembang.

\section{Metode Penelitian}

Penelitian ini merupakan jenis analitik observasional dengan desain studi potong lintang (cross sectional). Penelitian ini telah diajukan uji kelayakan etik (ethical clearance) oleh Komisi Etik Penelitian Rumah Sakit Umum Pusat Mohammad Hosein Palembang dan Fakultas Kedokteran Universitas Sriwijaya dengan nomor 478/kepkrsmhfkunsri/2019.

Subjek penelitian ini terdiri dari 30 orang yaitu 15 subjek perempuan menopause dan 15 subjek perempuan pascamenopause. Seluruh subjek merupakan pengguna gigi tiruan lengkap rahang atas dan rahang bawah yang melakukan perawatan di Rumah Sakit Khusus Gigi dan Mulut (RSKGM) Sumatera Selatan. Seluruh subjek adalah subjek sehat dengan rentang usia 4078 tahun. Subjek menopause yang dilibatkan dalam penelitian adalah subjek yang telah berhenti menstruasi selama $1-<3$ tahun dan subjek pascamenopause adalah subjek yang telah berhenti menstruasi selama $\geq 3$ tahun. Seluruh subjek yang dilibatkan telah menggunakan gigi tiruan lengkap rahang atas dan rahang bawah selama 1-2 tahun. Subjek yang mengalami kelainan sendi temporomandibula (TMJ) dan terdapat lesi di mukosa rongga mulut tidak diikutsertakan dalam penelitian ini. Seluruh subjek yang memenuhi kriteria diberikan penjelasan mengenai prosedur penelitian dan diminta untuk menandatangani informed consent.

Penelitian dilakukan dengan metode permen karet menggunakan color-changeable chewing gum (Xylitol, Japan) untuk mengukur kemampuan mastikasi subjek. Penilaian dilakukan dengan mengamati perubahan warna permen karet secara visual. Subjek yang diikutsertakan diberikan instruksi untuk berkumur dengan air, kemudian diberikan masing-masing 1 buah permen karet untuk dilakukan mastikasi sebanyak 100 kali. Permen karet yang telah dikunyah diletakkan pada plastik bening yang diletakkan di atas selembar kertas putih untuk diamati perubahan warna secara visual. Warna permen karet dibagi menjadi 5 tingkatan yaitu tingkat 1 
dan 2 diklasifikasikan sebagai kemampuan mastikasi buruk dan tingkat 3,4, dan 5 sebagai kemampuan mastikasi baik (Gambar 1).

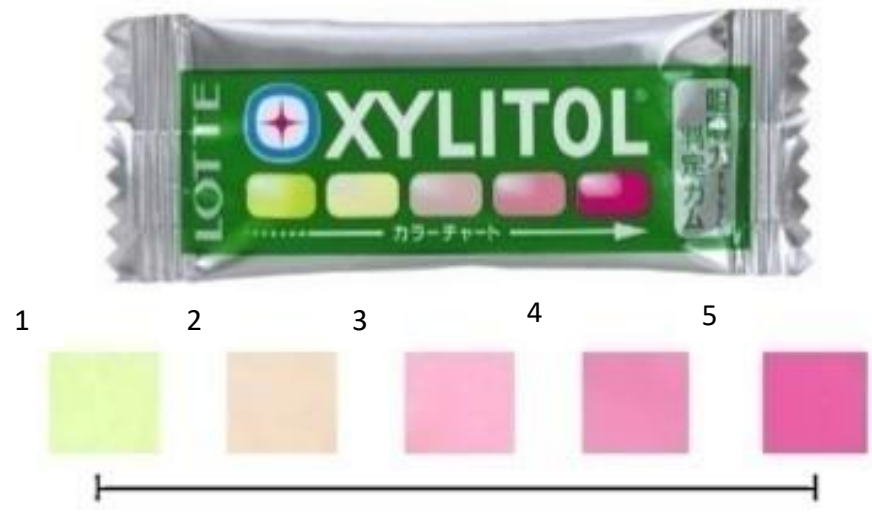

Gambar 1. Skala warna Color-Changeable Chewing Gum

Data hasil pengukuran kemampuan mastikasi kedua kelompok diuji menggunakan uji statistik chi-square dengan jenis tabel 2x2 dengan nilai signifikansi kurang dari 0,05 .

\section{Hasil}

Tabel 1. Perbandingan Kemampuan Mastikasi Subjek Berdasarkan Kelompok Usia

\begin{tabular}{lccccc}
\hline \multirow{2}{*}{ Kelompok } & $\begin{array}{c}\text { Rata-rata } \\
\text { Usia }\end{array}$ & $\begin{array}{c}\text { Rata-rata } \\
\text { Skala Warna }\end{array}$ & \multicolumn{2}{c}{$\begin{array}{c}\text { Kemampuan } \\
\text { Mastikasi Subjek }\end{array}$} & \multirow{2}{*}{ Selisih } \\
\cline { 5 - 6 } & (tahun) & Permen Karet & Baik & Buruk & \\
\hline Menopause (N=15) & 53,27 & 3,67 (Baik) & $15(100 \%)$ & $0(0 \%)$ & \\
Pascamenopause (N=15) & 64 & 2,13 (Buruk) & $4(26,7 \%)$ & $11(73,3 \%)$ & \\
\hline Total & & & $19(63,3 \%)$ & $11(36,7 \%)$ & $26,6 \%$ \\
\hline
\end{tabular}

Tabel 1 menunjukkan besar persentase kemampuan mastikasi yang baik lebih tinggi dibandingkan kemampuan mastikasi yang buruk dengan selisih persentase sebesar 26,6\% pada subjek penelitian secara keseluruhan. Persentase kemampuan mastikasi yang baik didominasi oleh kelompok subjek menopause pengguna gigi tiruan lengkap. Secara persentase, subjek menopause pengguna gigi tiruan lengkap mempunyai kemampuan mastikasi yang lebih baik dibandingkan subjek pascamenopause pengguna gigi tiruan lengkap.

Tabel 2. Analisis Uji Chi-SquarePerbandingan Kemampuan Mastikasi Subjek Berdasarkan Kelompok Usia

\begin{tabular}{lcccc}
\hline \multirow{2}{*}{ Kelompok } & N & \multicolumn{2}{c}{ KemampuanMastikasi Subjek } & \multirow{2}{*}{ P-value } \\
\cline { 3 - 4 } & & Baik & Buruk & \\
\hline Menopause & 15 & $15(100 \%)$ & $0(0 \%)$ & \multirow{2}{*}{$0,00^{*}$} \\
Pascamenopause & 15 & $4(26,7 \%)$ & $11(73,3 \%)$ & \\
\hline
\end{tabular}

Keterangan: *signifikan $(\mathrm{p}<0,05)$, Uji chi-square 
Berdasarkan tabel 2, hasil uji statistik Chi-squaremenunjukkan nilai $\mathrm{p}=0,00$. Hal tersebut menunjukkan bahwa terdapat perbedaan bermakna antara kemampuan mastikasi perempuan menopause pengguna gigi tiruan lengkap dengan perempuan pascamenopause pengguna gigi tiruan lengkap $(\mathrm{p}<0,05)$.

\section{Pembahasan}

Berdasarkan hasil penelitian, terdapat perbedaan kemampuan mastikasi antara kelompok perempuan menopause pengguna gigi tiruan lengkap dengan kelompok pascamenopause pengguna gigi tiruan lengkap. Perempuan menopause mengalami periode ketika siklus menstruasi berhenti selama 1 tahun dan terjadi penurunan estrogen yang berlanjut. Perempuan pascamenopause telah mengalami masa tersebut selama 3-5 tahun. ${ }^{8}$ Hasil penelitian menunjukkan bahwa terdapat variasi dalam skala warna permen karet baik pada kelompok menopause maupun pascamenopause. Variasi tersebut disebabkan oleh adanya perbedaan intensitas pemakaian gigi tiruan lengkap pada subjek.Fenlon dkk menyatakan bahwa pemakaian gigi tiruan lengkap secara intens akan menghasilkan kemampuan mastikasi yang semakin baik. ${ }^{16}$ Gigi tiruan lengkap mengurangi jumlah resorpsi tulang alveolar dan memberikan beban yang seimbang pada tulang alveolar sehingga terjadi peningkatan kemampuan mastikasi. ${ }^{11,17}$ Matsuda dkk menjelaskan bahwa penggunaan gigi tiruan lengkap meningkatkan kekuatan mastikasi dari $84 \mathrm{~N}$ menjadi $165 \mathrm{~N} .{ }^{15}$ Kelompok pascamenopause memiliki rata-rata skala perubahan warna dalam kategori buruk, namun terdapat subjek pascamenopause yang masih memiliki skala perubahan warna dalam kategori baik, hal ini dipengaruhi juga oleh lama menopause. Data menunjukkan bahwa kelompok pascamenopause yang telah mengalami menopause $\leq 5$ tahun masih memiliki kemampuan mastikasi yang baik. Perbedaan kemampuan mastikasi kelompok menopause dan pascamenopause disebabkan oleh penurunan kadar hormon estrogen yang terjadi pada perempuan menopause dan pascamenopause. ${ }^{5}$

Hasil penelitian, menunjukkan terdapat perbedaan bermakna kemampuan mastikasi pengguna gigi tiruan lengkap antara kelompok perempuan menopause dengan kelompok pascamenopause. Penelitian ini menunjukkan bahwa faktor durasi menopause mempengaruhi kemampuan mastikasi. Penurunan kadar estrogen berlanjut yang dialami perempuan menopause dan pascamenopause mengakibatkan terhambatnya pembentukan dan penyerapan kalsium oleh tulang, sehingga terjadi penurunan kepadatan tulang. ${ }^{8}$ Penurunan kepadatan tulang akan mempengaruhi penurunan massa otot dan kekuatan mastikasi. ${ }^{5,18}$ Sultan dkk melaporkan bahwa terjadi kehilangan kepadatan tulang kortikal dan trabekular sebesar 2-3\% dan 4-8\% pada masa pascamenopause akibat penurunan kadar hormon estrogen yang terus berlanjut selama kurun waktu yang lama. ${ }^{19}$ Perempuan pascamenopause mengalami kehilangan kadar hormon estrogen yang lebih banyak akibat durasi menopause yang lebih lama sehingga mengakibatkan kemampuan mastikasi semakin menurun.

Penurunan kadar hormon estrogen juga akan mempengaruhi laju alir saliva. Jumlah saliva yang dihasilkan dalam rongga mulut mempengaruhi proses mastikasi. Saliva membantu melumas makanan dalam proses mastikasi. ${ }^{20}$ Penurunan laju alir saliva tersebut terjadi akibat 
adanya penurunan fungsi kelenjar saliva yang disebabkan perubahan hormon estrogen. ${ }^{18,21}$ Saluja dkk yang menyatakan bahwa perempuan menopause dan pascamenopause mengalami penurunan laju alir saliva. ${ }^{18}$ Matsuda dkk menyatakan bahwa gigi tiruan lengkap dapat merangsang peningkatan laju alir saliva baik yang terstimulasi maupun tidak terstimulasi. ${ }^{15}$ Data menunjukkan bahwa perempuan menopause mempunyai kemampuan mastikasi yang baik dibandingkan perempuan pascamenopause. Perempuan pascamenopause telah mengalami penurunan kadar estrogen yang lebih banyak sehingga diprediksi menyebabkan laju alir saliva menjadi semakin rendah sehingga mempengaruhi proses mastikasi menggunakan gigi tiruan lengkap. Pengukuran kadar hormon estrogen dapat dilakukan untuk lebih membuktikan perbandingan kemampuan mastikasi pada perempuan menopause dan pascamenopause pengguna gigi tiruan lengkap.

Kemampuan mastikasi juga dapat dipengaruhi oleh preferensi sisi mastikasi yang pada penelitian ini tidak diperhatikan, sehingga penelitian selanjutnya dapat dilakukan dengan memperhatikan preferensi sisi mastikasi. ${ }^{22}$ Kekurangan penelitian ini juga adalah penilaian kemampuan mastikasi adalah secara visual berdasarkan perubahan warna permen karet, sehingga bisa bersifat subjektif. Penggunaan kolorimeter untuk menilai perubahan warna bisa sebagai alternatif untuk penelitan selanjutnya ${ }^{23}$.

Hasil penelitian ini menunjukkan penggunaan gigi tiruan lengkap bisa membantu fungsi mastikasi pada perempuan menopause maupun pascamenopause. Faktor penunjang lain seperti nutrisi dan saliva perlu diperhatikan untuk mendukung keberhasilan perawatan gigi tiruan lengkap agar dapat mengembalikan kemampuan mastikasi perempuan pascamenopause secara optimal.

\section{Kesimpulan}

Kesimpulan penelitian ini menunjukkan bahwa terdapat perbedaan kemampuan mastikasi antara kelompok menopause dengan pascamenopause pengguna gigi tiruan lengkap.Kemampuan mastikasi kelompok menopause lebih baik dibandingkan pascamenopause pengguna gigi tiruan lengkap.

\section{Daftar Pustaka}

1. Agrawal A, Tuman PR. Role of mastication in the digestion process: a review. Journal of Chronotheraphy and Drug Delivery. 2016; 7(1): 21-4.

2. Palinkas M, Flavia AC, Selma S, Tania FB, Camila AM, Marisa S, et al. Aging of masticatory efficiency in healthy subject: electromyographic analysis - part 2. Acta Odontol. 2013; 26(3): 161-6.

3. Isabel CA, Marcos RM, Andries VB, Gustavo HG, Jose CR, Luciano JP. The relationship between masticatory and swallowing behaviors and body weight. Physiology and Behaviour 151. 2015: 314-9.

4. Lamster IB, Asadourian L, Del CT, Friedman PK. The aging mouth: differentiating normal aging from disease. Periondotology 2000. 2016; 72(1); 96-107. 
5. Riadiani B, Ratna SD, Nina A, Farisza G. Tooth loss and perceived masticatory ability in post-menopausal women. Journal of Dentistry Indonesia. 2014; 21(1): 11-5.

6. Stachenfeld NS. Hormonal changes during menopause and the impact on fluid regulation. Reproductive Sciences. 2014; 21(5): 555-61.

7. Jose JM, Maria NM. Comparative study on hormonal abnormalities in infertile woman. International Journal of Current Research. 2017; 9(10): 58412-6.

8. Mulyaningsih S, Dyah PP. Klimakterium: masalah dan penanganannya dalam perspektif kebidanan. Yogjakarta: Pustaka Baru Press. 2018. p.19-22.

9. Johnston BD, Wendy EW. The ovariectomized rat as a model for studying alveolar bone loss in postmenopausal women. BioMed Research International. 2015; 2015(8): 1-12.

10. Vassconcelos PB, Marcelo P, Luiz G, Simone R, Carla MS, Moara R, et al. The influence of maxillary and mandibular osteoporosis on maximal bite force and thickness of masticatory muscle. Acta Odontol. 2015; 28(1): 22-7.

11. Bodic F, Luc H, Emmanuelle L, Muchel FB, Daniel C. Bone loss and teeth. Joint Bone Spine. 2005; 72(3): 215-21.

12. Pamungkas PB, Chairani S, Purba R. Performance of mastication in menopausal women in Palembang. Jurnal Kesehatan Gigi. 2019;6(4):113-7.

13. Sivakumar I, Suresh S, Alluri VR, Bheemaligeshwaea, Rao. Changes in oral health-related quality of life in elderly edentulous patients after complete denture therapy and possible role of their initial expectation: a follow-up study. Journal of Prosthodontics. 2014; 24(6): 452-6.

14. Veeraiyan DN. Textbook of prosthodontics $2^{\text {nd }}$ ed. New Delhi: Jaypee Brothers Publisher Ltd. 2017. p.4-7; p.23.

15. Matsuda K, Kazunori I, Taiji O, Ryosuke K, Yashinobu M. Increase of salivary flow rate along with imporved occlusal force after the replacement of complete dentures. Oral Surg Oral Med Oral Pathol Oral Radiol Endod. 2009; 108: 2011-5.

16. Fenlon, MR, Sherrif M. Investigation of new complete denture quality and patients' satisfaction with and use of dentures after two years. Journal of Dentistry. 2004; 32: 327-33.

17. Guiglia R, Olga DF, Lucio LR, Delia S, Giovan BR, Giuseppina C. Osteoporosis, jawbones and periodontal disease. Med Oral Patol Oral Cir Bucal. 2013; 18(1): e93-9.

18. Saluja P, Vishwaprakash S, Aparna D, Manpreet A, Vibha H, Ajay M. Comparative evaluation of the effect of menstruation, pregnancy and menopause on salivary flow rate, $\mathrm{pH}$ and gustatory function. Journal of Clinical and Diagnostic Research. 2014; 8(10): 81-5.

19. Sultan N, Jyoti R. Association between periodontal disease and bone mineral density in postmenopausal women: a cross sectional study. Med Oral Patol Cir Bucal. 2011; 16(3): e440-7.

20. Carpenter GH. The secretion, components, and properties of saliva. Annual Review Food Science and Technology. 2012; 14: 13.1-13.10.

21. Minicucci EM, Pires RBC, Viera RA, Miot HA, Sposto MR. Assessing the impact of menopause on salivary flow and xerostomia. Australian Dental Journal. 2013; 58: 230-4.

22. Gomes SGF, Custodio W, Silva J, Jufer M, Cury AA, Garcia RC. Correlation of mastication and masticatory movements and effect of chewing side preference. Braz Dent J. 2010;21(4):351-5.

23. Stjernfeldt PE, Petteri S, Inger W, Anne-Marie B. Systematic review of measurement properties of methods for objectively assessing masticatory performance. Clinical and Experimental Dental Research. 2019;5(1):76-104. 